\title{
ULTRASOUND GUIDED SUPRACLAVICULAR BRACHIAL PLEXUS BLOCK WITH AND WITHOUT MAGNESIUM SULPHATE: A COMPARATIVE STUDY
}

\author{
Narmatha Yangtse1, Shanmugavelu $G^{2}$, Jeyabaskaran $A^{3}$ \\ ${ }^{1}$ Assistant Professor, Department of Anaesthesiology, Coimbatore Medical College and Hospital. \\ ${ }^{2}$ Associate Professor, Department of Anaesthesiology, Coimbatore Medical College and Hospital. \\ ${ }_{3}^{3}$ Associate Professor, Department of Anaesthesiology, Coimbatore Medical College and Hospital.
}

\begin{abstract}
\section{BACKGROUND}

Many drugs have been used as adjuvants to local anaesthetics to prolong the duration of analgesia after a peripheral nerve block. In this study, we evaluate the effects of adding MgSO4 to local anaesthetics in supraclavicular block to prolong the duration of analgesia.
\end{abstract}

\section{AIM AND OBJECTIVES}

To compare the effect of addition of MgSO4 to local anaesthetics in supraclavicular block and study the onset of sensory blockade, motor blockade, duration of motor blockade and duration of analgesia.

\section{MATERIALS AND METHOD}

This study was conducted in 60 patients of ASA Grade 1 and 2, undergoing upper limb orthopaedic procedures using ultrasoundguided supraclavicular block after getting Ethical Committee approval. They were divided into two groups of 30 each. Group 1 received $1.5 \%$ adrenalized lignocaine $13 \mathrm{~mL}+0.5 \%$ bupivacaine $13 \mathrm{~mL}$ and $2 \mathrm{~mL}$ of $10 \%$ MgSO 4 . Group 2 received $1.5 \%$ adrenalized lignocaine $13 \mathrm{~mL}+0.5 \%$ bupivacaine $13 \mathrm{~mL}$ and $2 \mathrm{~mL}$ of $0.9 \%$ normal saline. Following data were recorded for $24 \mathrm{hrs}$. after surgeryOnset and duration of sensory and motor blockade, analgesic duration using VAS pain score and side effects.

\section{RESULTS}

The duration of analgesia was significantly longer in MgSO4 group than in saline group. In MgSO4 group, duration was 834 minutes Vs 276 minutes in normal saline group. The $p$ value was $<0.0001$, which was significant. But onset times of sensory and motor blockade were not significantly different between the two groups. Also there was no significant difference observed in the side effects between the groups.

\section{CONCLUSION}

The addition of 10\% MgSO4 $2 \mathrm{~mL}(200 \mathrm{mg}$ ) as adjuvant to local anaesthetic for supraclavicular block prolongs the duration of analgesia.

\section{KEYWORDS}

Supraclavicular Block, Magnesium Sulphate.

HOW TO CITE THIS ARTICLE: Yangtse N, Shanmugavelu G, Jeyabaskaran A. Ultrasound guided supraclavicular brachial plexus block with and without magnesium sulphate: a comparative study. J. Evolution Med. Dent. Sci. 2016;5(39):2386-2389,

DOI: $10.14260 /$ jemds/2016/555

\section{INTRODUCTION}

Brachial plexus block is widely employed for upper limb orthopaedic procedures. A number of drugs like clonidine, morphine, buprenorphine, ketamine are used as adjuvants but they have their own pros and cons like morphine and buprenorphine can cause heavy sedation and respiratory depression. Clonidine can cause hypotension, ketamine is more prone for hallucinations and unpleasant feelings.

$\mathrm{MgSO} 4$ has been shown to have antinociceptive effects by blocking the NMDA receptors and associated $\mathrm{Ca}+$ channels, thus preventing the central sensitization caused by peripheral

Financial or Other, Competing Interest: None.

Submission 31-03-2016, Peer Review 23-04-2016,

Acceptance 30-04-2016, Published 16-05-2016.

Corresponding Author:

Dr. Narmatha Yangtse

Assistant Professor,

Department of Anaesthesiology,

Coimbatore Medical College Hospital.

E-mail: yangtsehere@yahoo.co.in

DOI: $10.14260 /$ jemds $/ 2016 / 555$ nociceptive stimulation, thus MgSO4 was selected as an adjuvant to local anaesthetics in this study, as it prolongs the duration of analgesia in the post-operative period.

\section{AIM AND OBJECTIVES}

To analyse the effect of adjuvant MgSO4 to local anaesthetics on

-onset of sensory block.

-onset of motor block.

-duration of motor block.

-duration of analgesia.

\section{MATERIALS AND METHODS}

This study was conducted in 60 patients belonging to ASA Gr I and Gr II, aged between 20-60 yrs. after obtaining approval from Ethical Committee during March 2009 to Sep. 2009 in $\mathrm{CMCH}$. All patients were posted for upper limb surgeries below the shoulder and received supraclavicular brachial plexus block using USG guided nerve block. This was a randomized, prospective double blinded and controlled study. 


\section{Exclusion Criteria}

- ASA > GR II.

- Patients with cardiac, respiratory, liver or renal disorders.

- Pts. on anticoagulants or bleeding disorders.

- Pts. on chronic treatment with ca channel blockers.

- Local infection at the injection site.

- Pregnancy.

- Neurological deficit involving the brachial plexus.

GP I - (M GP) - patients in this group received 1.5\% adrenalized lignocaine $13 \mathrm{~mL}$ and $0.5 \%$ bupivacaine $13 \mathrm{~mL}$ plus $10 \%$ MgSO4-2 mL. Total volume of $28 \mathrm{~mL}$. (Adrenalized lignocaine-not exceeding $7 \mathrm{mg} / \mathrm{kg}$ bw., bupivacaine- $2 \mathrm{mg} / \mathrm{kg}$ bw.).

GP II (CGP) - patients in this group received 1.5\% adrenalized lignocaine $13 \mathrm{~mL}, 0.5 \%$ Bupivacaine $13 \mathrm{~mL}$ plus $0.9 \%$ saline $2 \mathrm{~mL}$, total of $28 \mathrm{~mL}$.

Routine basic investigations done. (CBC, RBS, UREA, CREATININE, X-RAY, ECG).

The injection mixture was prepared immediately before surgery by anaesthetist, who is not involved in this study.

Patient was connected to multi-monitor, IV fluid started and was given midazolam $0.02 \mathrm{mg} / \mathrm{kg}$ IV before the block and $0_{2}$ in venti mask kept at rate of 2 litres/min. Venturi mask is fixed performance device and we used blue venti mask with 2 lit/min, which provides $24 \% \mathrm{O}_{2}$ and has an air: oxygen entrainment ratio of 23:1 (The possibility of rebreathing is same in both the groups, so it does not make any significant difference in the study.)

Patient was kept in supine posture with head turned away from the side to be blocked. We used ultrasound to identify the brachial plexus at the level of trunks. After local infiltration of the skin with $1 \%$ lignocaine, a $5 \mathrm{~cm}, 22 \mathrm{~g}$ insulated needle was advanced using an in-lane technique. After identifying the plexus, local anaesthetic drug was given after repeated intermittent negative aspiration for blood and the spread of drug around the plexus was observed under real time ultrasound guidance. This was done by an anaesthesiologist, who was experienced in this technique and blinded to this study. The data was recorded by a post graduate, who was blinded to the patient groups.

\section{Following Parameters Were Studied}

1. Onset of sensory block - After the end of drug administration every $5 \mathrm{~min}$ till $30 \mathrm{~min}$. Sensory block was assessed by pinprick method. ( $0=$ normal sensation, $1=$ lack of sensation to pin prick, 2 =lack of sensation to touch).

2. Onset of motor block - After the end of drug administration, motor block was assessed every 5 min till $30 \mathrm{~min}$. $(0=$ no block (Normally moving), 1=partial block (Diminished movement, but not total absent of motor strength (PARESIS)), 2=complete block (Unable to elevate the arm full lack of movement).

3. Duration of motor block - This was assessed every $1 \mathrm{hr}$. by asking the patient to move fingers and time was recorded, if she/he moves that was taken as cessation of motor block.

4. Duration of analgesia - Postoperative follow-up was carried out in the recovery and postoperative ward for 24 hrs. Postoperative pain was noted using VAS for pain $(0-10)$ every half hour for first $10 \mathrm{hrs}$., then hourly till $24 \mathrm{hrs}$.
If the patient experiences VAS score of more than 6 , rescue analgesia was given and it is taken as end point.

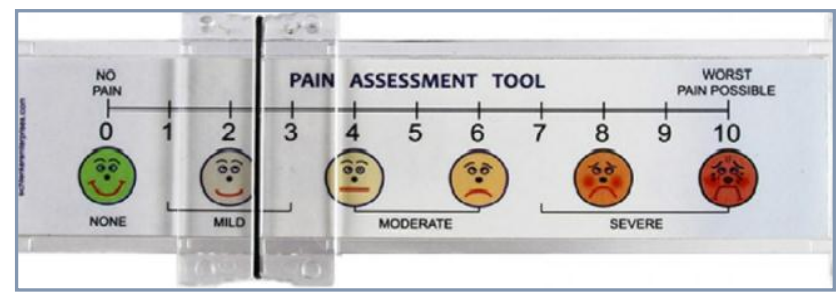

Duration of analgesia was taken as time interval from administration of local anaesthetic to the administration of first dose of rescue analgesia.

5. Monitoring of side effects - Incidence of drowsiness, nausea, vomiting, bradycardia and respiratory depression were noted at 4, 8, $12 \mathrm{hrs}$. after surgery.

\section{Statistical Analysis}

The data obtained were analysed using unpaired ' $t$ ' test. If $\mathrm{p}>.05$, means there is no significant difference between means of two groups. If $p=.05$, means there is significant difference at $5 \%$ level of significance. If $\mathrm{p}<.01$, shows data is significant at $1 \%$ level of significance.

\section{RESULTS}

The patients were divided into 2 groups. In Group 1 magnesium sulphate was added to local anaesthetic and in Group 2 saline was mixed with local anaesthetic for control.

\section{Demographic Data}

\begin{tabular}{|c|c|c|c|}
\hline Groups & Group 1 & Group 2 & P Value \\
\hline Mean age (Yrs.) & 28.04 & 30.02 & $>0.05$ \\
\hline $\begin{array}{c}\text { Duration of surgery } \\
\text { (min.) }\end{array}$ & 167.4 & 154.2 & $>0.05$ \\
\hline Weight (kg) & 57.39 & 61.52 & $>0.05$ \\
\hline Height (cm) & 169 & 168 & $>0.05$ \\
\hline
\end{tabular}

Group 1: Magnesium Sulphate, Group 2: Saline Control

\section{Demographic Data}
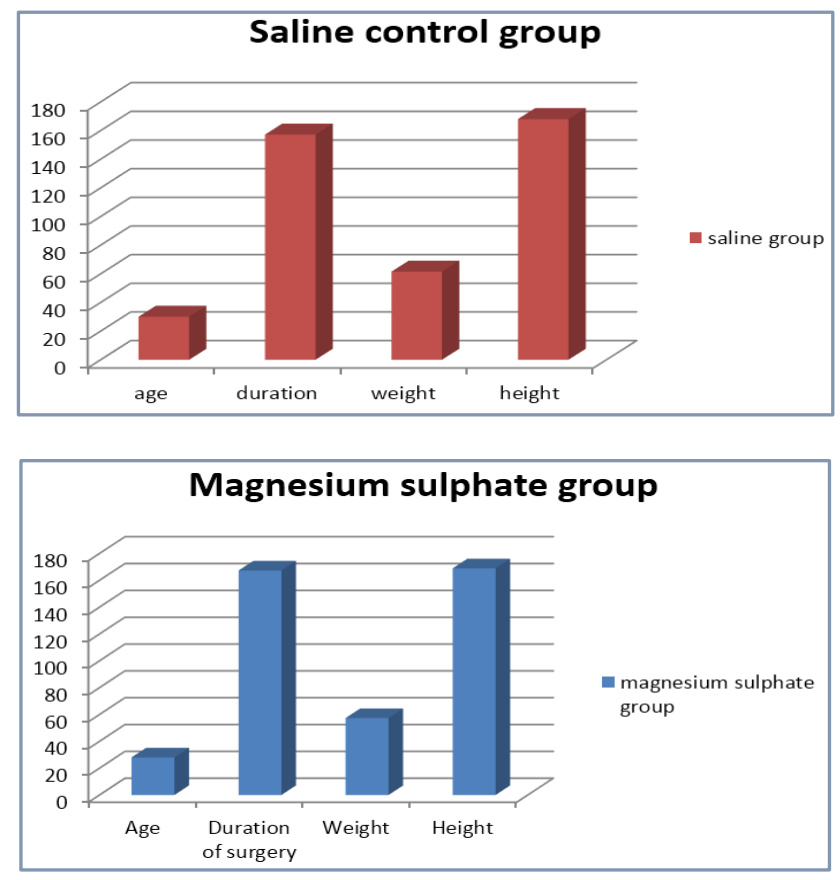
There was no significant difference noted between the 2 groups in demographic characteristics.

\section{Sex Distribution}

\begin{tabular}{|c|c|c|c|}
\hline Groups & Group 1 & Group 2 & P Value \\
\hline Male & 16 & 17 & $>0.05$ \\
\hline Female & 14 & 13 & $>0.05$ \\
\hline
\end{tabular}

\section{Sex Distribution}

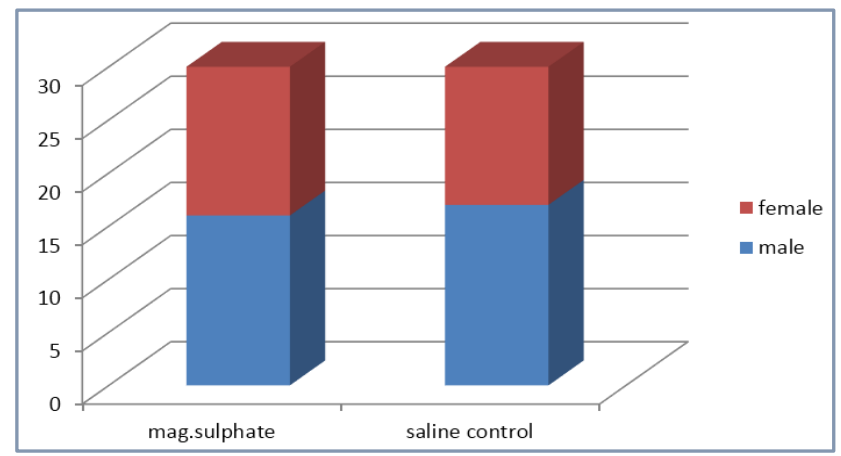

No significant differences observed in sex distribution.

\section{Duration of Analgesia}

\begin{tabular}{|c|c|c|c|}
\hline Groups & Group 1 & Group 2 & P Value \\
\hline $\begin{array}{c}\text { Onset of sensory } \\
\text { block (Min.) }\end{array}$ & 5.92 & 6.6 & 0.4101 \\
\hline $\begin{array}{c}\text { Onset of motor } \\
\text { block (Min.) }\end{array}$ & 15.8 & 16.6 & 0.6005 \\
\hline $\begin{array}{c}\text { Duration of } \\
\text { analgesia (Min.) }\end{array}$ & 834 & 276 & $<0.0001$ \\
\hline $\begin{array}{c}\text { Duration of } \\
\text { motor } \\
\text { block (Min.) }\end{array}$ & 302 & 296 & 0.876 \\
\hline
\end{tabular}

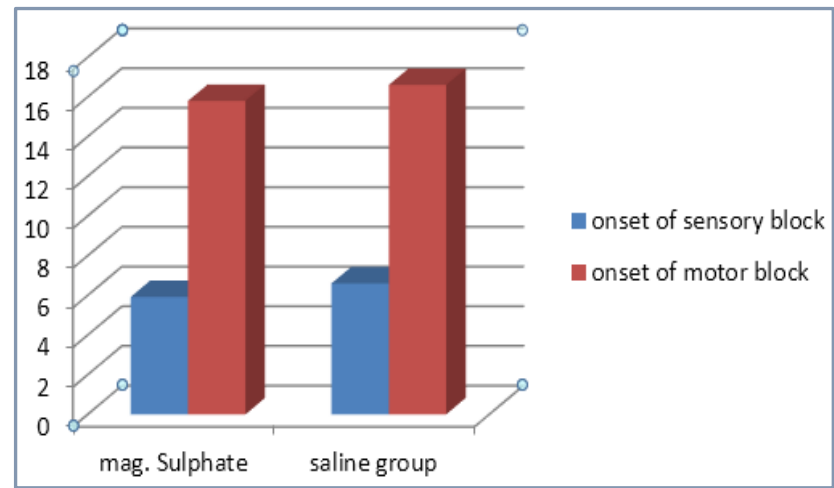

There was no difference observed in the onset of action of sensory and motor blockade.

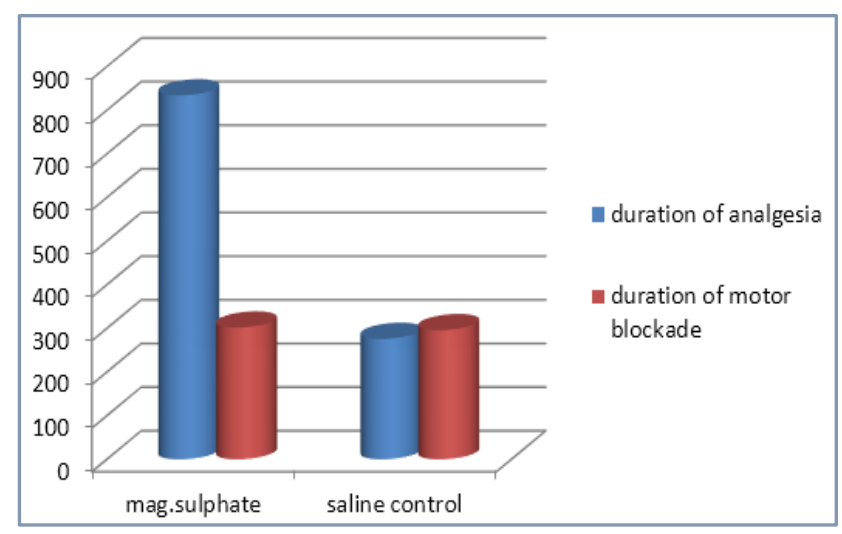

There is a significant increase in duration of analgesia in magnesium sulphate group than control group without any difference in duration of motor blockade.

Complications of Supraclavicular Nerve Block

\begin{tabular}{|c|c|c|c|c|c|c|c|c|}
\hline & \multicolumn{4}{|c|}{ Group 1 } & \multicolumn{5}{c|}{ Group 2 } \\
\hline & $\mathbf{4}$ hrs. & $\mathbf{8}$ hrs. & $\mathbf{1 2}$ hrs. & 24 hrs. & 4 hrs. & $\mathbf{8}$ hrs. & 12 hrs. & 24 hrs. \\
\hline Nausea & 1 & 2 & 4 & 8 & 2 & 2 & 4 & 9 \\
\hline Vomiting & 0 & 1 & 1 & 2 & 1 & 1 & 0 & 3 \\
\hline Pruritus & 0 & 0 & 0 & 1 & 0 & 0 & 0 & 2 \\
\hline Rescue analgesics & 0 & 1 & 0 & 2 & 0 & 0 & 0 & 2 \\
\hline Respiratory depression & 0 & 0 & 0 & 0 & 0 & 0 & 0 & 0 \\
\hline
\end{tabular}

\section{Duration of Analgesia was Longer in Magnesium Sulphate Group than in Saline Group}

1. Mean onset of sensory block in magnesium sulphate group

2. Mean onset of sensory block in saline group

3. Mean onset of motor block in magnesium sulphate group

4. Mean onset of motor block in saline group

5. Mean duration of analgesia in magnesium sulphate group

6. Mean duration of analgesia in saline group

7. Mean duration of motor block in saline group

8. Mean duration of motor block in magnesium sulphate group

\section{DISCUSSION}

Many studies have investigated the systemic neuraxial administration of magnesium sulphate, whereas studies on peripheral neuraxial block are limited. The primary hypothesis for the analgesic properties of magnesium on peripheral nerve is the surface change theory by Akutagawa et al.(1)

In his study, he showed blocking a nerve bundle with external magnesium sulphate enhanced the blockade of local anaesthetic. Mert et al(2) showed high concentration of bivalent ions $\left(\mathrm{Mg}^{2+}, \mathrm{Ca}^{2+}\right)$ attracted the negative charges of the outer
$5.92+2.8 \mathrm{~min}$.

$6.6+2.95 \mathrm{~min}$.

$15.8+5.6 \mathrm{~min}$

$16.65 .11 \mathrm{~min}$.

$834+78.1 \mathrm{~min}$

$276+38.2 \mathrm{~min}$

$296 \mathrm{~min}$.

$302 \mathrm{~min}$

membrane, surface affected $\mathrm{Na}+$ channel gain and could cause hyperpolarization.

If the nerve fiber is hyperpolarized, it is difficult to achieve the threshold level and it can cause nerve conduction block.

Another mechanism for analgesia action of magnesium sulphate is voltage dependent antagonism of NMDA receptors that leads to prevention of central sensitization from peripheral nociceptive stimulation and decrease in pain. 
However, the involvement of NMDA receptor in the peripheral nerve block is less certain.

A study by Guntz et al(3) showed prolonged duration of sensory and motor block when magnesium sulphate is added to prilocaine for axillary block.

A study by A. R. Lee, Hyewonyi.(4) in 2011-published in Canadian Anaesthesiology Society showed MgSO4 added to interscalene block with $0.5 \%$ bupivacaine prolongs the duration of analgesia. K Al Refaey, EM Usama.(5) in their study in 2016 showed adding MgSO4 to Bupivacaine in TAP block for post-op pain relief for laparoscopic cholecystectomy patients increased the duration of analgesia and reduced the need for post-op analgesia.

Soave et $\mathrm{al}^{(6)}$ showed in their study that the level of magnesium in blood and cerebrospinal fluid was significantly higher in the group given magnesium in pre-eclamptic patients treated with magnesium sulphate $(\mathrm{p}<0.05)$, and the mean duration sensory block time was significantly longer in intravenous magnesium group than in other groups $(p<0.05)$.

Bilir et al(7) showed co-administration of magnesium for post-operative epidural analgesia results in a reduction in fentanyl consumption without any side effects. The groups were similar with respect to haemodynamic and respiratory variables, sedation, pruritus and nausea. Ciccone et $\mathrm{al}^{(8)}$ in their study showed the interscalene regional block provided more pain relief than infusion pumps immediately after arthroscopic shoulder surgery. Infusion pumps did not significantly reduce pain levels after the blocks wore off.

Gyu Choi, Young Soon Choi, Yong Ho Kim, JinYa Min.(9) In their study on the effects of post-operative brachial plexus block using $\mathrm{MgSO} 4$ in postoperative analgesia in upper extremity showed that in axillary brachial plexus block using $\mathrm{MgSO} 4$, there is no difference in the level of post-operative pain and opioid consumption between groups.

Lysakowski et al(10) in their trails do not provide convincing evidence that perioperative magnesium may have favourable effects on post-operative pain intensity and analgesic requirements. It may be worthwhile to further study the role of magnesium as a supplement to post-operative analgesia, since this relatively harmless molecule is inexpensive and the biological basis for its potential antinociceptive effect is promising. Chen et al(11) in their study demonstrated that an intra-operative intra-articular magnesium sulphate and ropivacaine injection reduced the use of post-operative morphine.

Elsharnouby et al(12) showed in their study that magnesium combined with bupivacaine produces a reduction in postoperative pain when given intra-articularly in comparison to either bupivacaine or magnesium alone or to saline placebo.

A study by Ekmekci et al(13) showed that addition of magnesium to levobupivacaine prolongs the sensory and motor block duration without increasing side effects, enhances the quality of postoperative analgesia and increases patient satisfaction; however, the addition of magnesium delays the time to first mobilisation and decreases rescue analgesic requirements. Our study shows similar effect in prolongation of post-operative analgesia without increase in adverse effects. In their study, they have used $15 \%$ magnesium sulphate which showed a significant prolongation of motor blockade, we used $10 \%$ magnesium sulphate which does not show any significant increase in motor blockade.
This present study adds support to the effect of prolongation of analgesia when magnesium sulphate was used with local anaesthetics. This present study showed that addition of $10 \%$ magnesium sulphate $2 \mathrm{~mL}$ to the local anaesthetics prolonged the duration of analgesia in peripheral nerve block.

\section{CONCLUSION}

Addition of $10 \%$ magnesium sulphate $2 \mathrm{~mL}(200 \mathrm{mg}$ ) to local anaesthetics for supraclavicular brachial plexus block prolonged the duration of analgesia and improved the quality of post-operative analgesia with no difference in duration of motor blockade with similar side effects as when plain local anaesthetics.

\section{REFERENCES}

1. Akutagawa $T$, Kitahata IM, Saito $H$, et al. Magnesium enhances local anaesthetic nerve block of fros sciatic nerve. Anaesth Analog 1984;63(2):111-6.

2. Mert T, Gunes Y, Guven I, et al. Effects of calcium and magnesium on peripheral nerve conduction. Pol J Pharmcol 2003;55(1):25-30.

3. Gunduz A, Bilir A, Gulec S. Magnesium added to prilocaine prolongs the duration of axillary plexus block. Reg Anaesth Pain Med 2006;31(3):233-6.

4. Ae Ruoug Lee, Hye-won Yi, Justin Sangwook. Magnesium added to bupivacaine prolongs the duration of analgesia after interscalene block. Can J anaesth 2012;59(1):21-7.

5. Al Refaey K, Usama EM, Al-Hefnawey E. Adding magnesium sulphate to bupivacaine in transverses abdominis plane block for laparoscopic cholecystectomy patients for postoperative pain relief. Saudi J Anaesth 2016;10(2):18791.

6. Soave PM, Conti G, Costa R, et al. Magnesium and anaesthesia. Curr Drug Targets 2009;10(8):734-43.

7. Bilir A, Gulec S, Erkan A, et al. Epidural magnesium reduces post operative analgesic requirement. $\mathrm{Br} \mathrm{J}$ anaesthesia 2007;98(4):519-23.

8. Ciccone WJ, Busy TD, Weinstien DM, et al. Assessment of pain relief produced by interscalene regional block and infusion pump after arthroscopic shoulder surgery. Arthroscopy 2008;24(1):14-9.

9. In Gyu Choi, Young Soon Choi, Yong Ho Kim, et al. The effects of postoperative brachial plexus block using Mgso4 in postoperative analgesia in upper extremity surgery. Korean J Pain 2011;24(3):158-63.

10. Lysakowski C, Dumont L, Czarnetzki C, et al. Magnesium as an adjuvant to postoperative analgesia: a systematic review of randomized trials. Anaesth Analg 2007;104(6):1532-9.

11. Chen Y, Zhang Y, Zhu YL, et al. Efficacy and safety of an intraoperative intra-articular magnesium/ropivacaine injection for pain control following total knee arthroplasty. PLJ Int Med Res 2012;40(5):2032-40.

12. Elsharnouby NM, Eid HE, Abou Elezz NF, et al. Intraarticular injection of magnesium sulphate and/or bupivacaine for postoperative analgesia after arthroscopic knee surgery. Anaesth Analg 2008;106(5):1548-52. doi:10.1213/ane. 0b013e31816a67a8

13. Ekmekci P, Bengisun ZK, Akan B, et al. The effect of magnesium added to levobupivacaine for femoral nerve block on postoperative analgesia in patients undergoing ACL reconstruction. Knee Surg Sports Traumatol Arthrosc 2013;21(5):1119-24. doi: 10.1007/s00167-012-2093-4. 